\title{
Alterations in Adenylate Kinase Activity in Human PBMCs after In Vitro Exposure to Electromagnetic Field: Comparison between Extremely Low Frequency Electromagnetic Field (ELF) and Therapeutic Application of a Musically Modulated Electromagnetic Field (TAMMEF)
}

\author{
Antonietta Albanese, ${ }^{1}$ Emilio Battisti, ${ }^{1}$ Daniela Vannoni, ${ }^{2}$ Emilia Aceto, ${ }^{2}$ \\ Gianmichele Galassi, ${ }^{1}$ Stefania Giglioni, ${ }^{2}$ Valentina Tommassini, ${ }^{2}$ and Nicola Giordano ${ }^{2}$ \\ ${ }^{1}$ TAMMEF Centre, University of Siena, 53100 Siena, Italy \\ ${ }^{2}$ Department of Internal Medicine, Endocrine-Metabolic Sciences and Biochemistry, University of Siena, 53100 Siena, Italy
}

Correspondence should be addressed to Antonietta Albanese, albanesea@unisi.it

Received 12 March 2009; Revised 20 May 2009; Accepted 7 July 2009

Recommended by Richard Gomer

\begin{abstract}
This study investigated the effects of electromagnetic fields on enzymes involved in purine metabolism in human peripheral blood mononuclear cells in vitro. Cells were obtained from 20 volunteers. We tested both low-energy, extremely low frequency (ELF; $100-\mathrm{Hz}$ ) electromagnetic fields and the Therapeutic Application of Musically Modulated Electromagnetic Fields (TAMMEFs); the latter is characterized by variable frequencies, intensities, and wave shapes. Adenylate kinase activity was increased after ELF field exposure but decreased slightly after TAMMEF exposure. Neither of the two electromagnetic field affected the activities of the purine metabolism enzymes ecto- $5^{\prime}$-nucleotidase, adenosine deaminase, and adenosine kinase. We concluded that ELF fields may influence cellular electrical charge stability; stimulation of adenylate kinase activity could restore the cell to a state of equilibrium. In contrast, TAMMEF fields may be useful for maintaining and regulating the cellular electrical charge.
\end{abstract}

Copyright (C) 2009 Antonietta Albanese et al. This is an open access article distributed under the Creative Commons Attribution License, which permits unrestricted use, distribution, and reproduction in any medium, provided the original work is properly cited.

\section{Introduction}

The effects of electromagnetic fields (EMFs) on simple systems, such as colloids, particles in solution, and on living matter, have been investigated for many years [13]. While high-frequency EMFs produce microvibrations in the molecules that have been interpreted as resonance phenomena, ELFs induce slight and more modest actions [4-6]. Despite the large number of studies regarding the effects of EMFs, there is no consensus on the effects of pulsed EMFs on different biological targets. It is possible that EMFs with different characteristics, such as different waveforms, frequencies, and intensities, may have different or even opposing effects on cells. Interest on the effects of EMFs has greatly increased in recent years, especially in terms of their possible effects, their potential therapeutic and diagnostic applications. However, a comprehensive understanding is lacking about which frequency has the most positive effects and causes the least damage to living matter, or even to simple molecules. It is impossible to investigate the entire range of ELF EMFs: systematic exploration would require a limitless number of tests and could be impractical in terms of workload. However, it is possible to compare the effects of a specific EMF to a comprehensive reference EMF with parameters that change with time; such a reference EMF would involve combinations of different parameters.

At Physics Department of the University of Siena in Italy, a new system has been pioneered, termed the "Therapeutic Application of Musically Modulated Electromagnetic Field" or TAMMEF system, in which a large spectrum of low frequency EMFs are generated. The frequency, wave shape, and wave induction of the EMF varies using the TAMMEF 


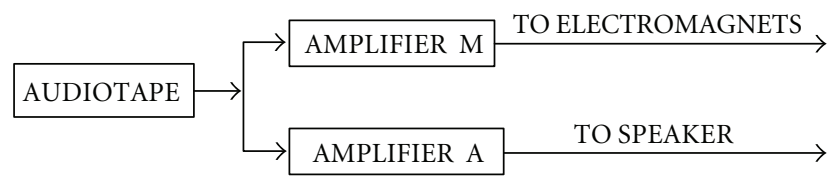

Scheme 1: Block diagram of the instruments used to generate ELF EMFs and TAMMEFs. The current produced by the audiotape is connected to the inputs of two amplifiers. The outgoing current from Amplifier $\mathrm{M}$ goes into electromagnets that generate the field (ELF or TAMMEF); the outgoing current from Amplifier A leads to a speaker, so that the piece can be contemporary listened. The two channels are separated because they have to be independent. The gain of Amplifier $M$ is adjusted during the calibration phase and is then kept at a fixed setting. This ensures that changes in the EMF depend only on the pilot signal. The gain of Amplifier A, which determines the sound intensity, is adaptable to changing needs.

system because the EMF is generated by a musical piece. This apparatus has been used in our institution for several years for therapeutic purposes, that is, to treat patients affected by several diseases, and the efficiency and effectiveness of the analgesic and anti-inflammatory effects of TAMMEF have been demonstrated [7-10].

Many published studies have examined the effects of EMFs on cell proliferation, cell cycle regulation, cellular differentiation, metabolism, and other physiological characteristics [11]. Although it is unlikely that ELF EMFs themselves have genotoxic effects, it is possible that some cellular processes are altered upon exposure to EMF.

In this study, we investigated and compared the in vitro effects of $100 \mathrm{~Hz}$ ELF EMF and the new TAMMEF system on cellular metabolism. The study was performed on peripheral blood mononuclear cells (PBMCs) from 20 healthy volunteers; these cells were used frequently in these studies because they are well characterized and relatively easy to obtain [12-15]. Specifically, we evaluated total cellular protein content and the activity of some key enzymes involved in nucleotide metabolism after exposure to EMFs. We chose to examine nucleotide metabolism because nucleotides are precursors of DNA and RNA, and the relationship of changes in nucleotide metabolism with some pathologies and drug interactions has been studied extensively [16-20]. The enzymes ecto- $5^{\prime}$-nucleotidase (EC 3.1.3.5) (ecto- $5^{\prime}$-NT), adenosine deaminase (EC 3.5.4.4) (ADA), and adenosine kinase (EC 2.7.1.20) (AdK) play important roles in intracellular adenosine homeostasis, while adenylate kinase (EC 2.7.4.3) (AK) regulates the cellular electrical charge [21-24].

\section{Materials and Methods}

2.1. Magnetic Field Production. A schematic drawing of the instruments used to generate ELF EMFs and TAMMEFs are shown in Scheme 1.

The EMF apparatus consisted of an audiotape player that sends a monochannel-microphone signal to 2 low-frequency amplifiers, $\mathrm{A}$ and $\mathrm{M}$, both with adjustable gain. The ELF field was modulated at a frequency of $100 \mathrm{~Hz}$ and was generated by an opposing pair of heteronomous polar expansions that made up the characteristic spatial conformation of the setup. The polar expansions consisted of the sides of two ironsilicon nuclei $(3 \times 4 \mathrm{~cm})$ joined by a ferromagnetic arc. The coils ( $4.5 \mathrm{~cm}$ long) consisted of 900 turns of copper wire ( $0.7 \mathrm{~mm}$ in diameter). The alternating current power supply was regulated to maintain the effective value of the oscillation amplitude at $\sim 10$ gauss at the midpoint of the interpolar distance $(30 \mathrm{~cm})$.

The TAMMEF apparatus was similar to the ELF apparatus; however, the audiotape contained a different signal, that is, a musical passage, which produced a suitably modulated EMF with varying frequencies and varying waveforms. We generally used a piece of classical music (i.e., Rachmaninov's Piano Concerto number 2 in C minor Op.18 for piano and orchestra) to generate a microphone signal, with the current from the amplifier going to a loudspeaker that played the musical passage, so that the piece can be contemporary listened during the therapy (in fact, it seems that the listening of the musical piece add a positive psychological effect to the EMF therapy).

The EMF generated in this way had characteristics that varied with time according to the musical signal; by simply changing the music, we could produce fields with varying frequencies, intensities, and wave shapes. Figure 1 shows representative ELF and TAMMEF signals.

To conduct an experiment, a $75-\mathrm{cm}^{2}$ flask containing the biological sample (about $70 \times 10^{6}$ cells) was positioned between the polar expansions in order to be directly in the generated EMF. The resulting functional modifications in the cellular microenvironment depended not only on the particular microenvironment or the EMF but also on changes in the field due to the responses of the cells. Figure 2 shows the position of the flask containing PBMCs during the 30-minute exposure to the EMF.

2.2. Cell Preparation. The research protocol was approved by our local ethics committee, and each blood donor provided informed written consent. Blood was donated by 20 healthy subjects, 10 males and 10 females, aged 25-45 years old. Fresh aliquots of Na-citrate blood $(30 \mathrm{~mL})$ were added to Histopaque 1077 (Sigma-Aldrich, St. Louis, Mo, USA) $1: 1$ and centrifuged (30 minutes, $750 \times \mathrm{g}, 4^{\circ} \mathrm{C}$, according to the protocol developed in our laboratory). The PBMC layer was removed and washed with a lyses mixture consisting of $155 \mathrm{mM} \mathrm{NH}_{4} \mathrm{Cl}, 10 \mathrm{mM} \mathrm{KHCO}_{3}$, and 0.1 EDTA for the lyses of the residual erythrocytes. We obtained five samples of PBMCs, from pools of 4 individuals, to diminish the effects of individual variation. The cells in each sample were counted using a Bürker chamber, divided equally into 4 aliquots of about $70 \times 10^{6}$ cells (one for each condition; described hereafter) then transferred to $75-\mathrm{cm}^{2}$ flasks containing DMEM and $10 \%$ FBS. Cells were incubated in a controlled atmosphere $\left(5 \% \mathrm{CO}_{2}, 95 \%\right.$ air), with controlled humidity and temperature conditions $\left(37^{\circ} \mathrm{C}\right)$ for $24-48$ hours, until treatment. Prior and at the end of the treatment with EMFs, cell survival was monitored 


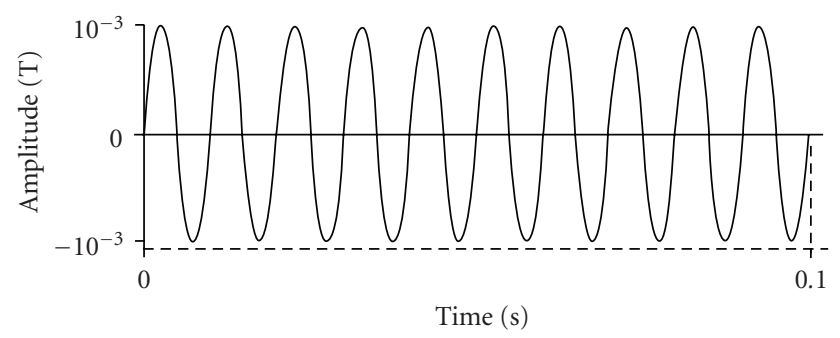

(a)

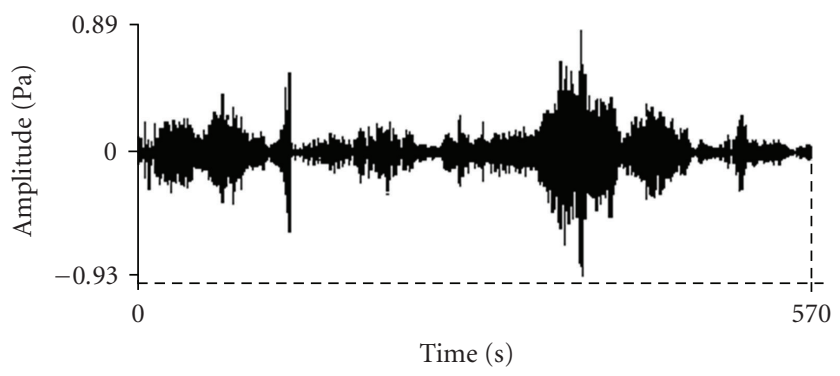

(b)

Figure 1: The ELF was produced by alternating-current electromagnets. The waveform was sinusoidal with a frequency of $100 \mathrm{~Hz}$; the amplitude was adjusted according to the distance between the polar expansions (a). The TAMMEF was produced by supplying the electromagnets with an outgoing current from an amplifier driven by a signal from recorded music (b). The signal shown in (b) contains extremely variable frequencies, amplitudes, and waveforms, and was generated by playing Rachmaninov's Piano Concerto number 2 in $\mathrm{C}$ minor Op.18 for piano and orchestra, the same used in the experiment. The oscillations are close together because the predominant frequencies are in the thousands of hertz.

using the alamarBlue assay (Invitrogen, Carlsbad, Calif, USA), which utilizes a water-soluble fluorimetric indicator based on a REDOX fluorescence indicator read at $590 \mathrm{~nm}$.

Cells that were not removed from the incubator (termed "T0" cells, as these cells represent the pretreatment controls) and cells that were removed from the incubator but not exposed to EMFs (termed "control" cells) served as the two reference controls. Other cells were exposed to either ELF EMFs or to TAMMEFs for 30 minutes. After treatment (or after 30 minutes for the T0 and control cells), the cells were submerged in an ultrasound bath for 10 seconds, ultracentrifuged for 60 minutes at $50,000 \times \mathrm{g}$, and aliquots of the supernatants were assayed for enzymatic activity $[25,26]$.

2.3. Enzyme Assays. To test for ADA activity: reactions contained $0.1 \mathrm{mM}$ adenosine, $50 \mathrm{mM}$ Tris- $\mathrm{HCl}(\mathrm{pH} 7.4)$, and supernatant (15-30 $\mu$ g protein). To test for ecto-5-NT activity: reactions contained $0.1 \mathrm{mM}$ AMP, $5 \mathrm{mM} \mathrm{MgCl}_{2}$, $50 \mathrm{mM}$ Tris- $\mathrm{HCl}$ ( $\mathrm{pH}$ 7.4), and supernatant (15-30 $\mu \mathrm{g}$ protein). Samples were incubated for 15 minutes at $37^{\circ} \mathrm{C}$, and the reactions were stopped by adding $0.2 \mathrm{~N} \mathrm{HClO}_{4}$; after centrifugation at $12,000 \mathrm{rpm}$ for 10 minutes at $4^{\circ} \mathrm{C}$, supernatants were neutralized with $0.2 \mathrm{~N} \mathrm{KOH}$, centrifuged to remove potassium perchlorate, and subjected to capillary electrophoresis analysis for quantification of the products. A multiple wavelength Biofocus 3000 Capillary Electrophoresis System (Bio-Rad, Hercules, Calif, USA) was used with an uncoated silica capillary $(40 \mathrm{~cm} \times 50 \mu \mathrm{m}$ id). The separation was performed with $20 \mathrm{mM}$ sodium borate buffer ( $\mathrm{pH} \mathrm{10)}$ and followed by UV detector at $254 \mathrm{~nm}$. Reaction products were identified on the basis of their retention times compared to standards analyzed under the same conditions.

To test for AdK activity: the reactions contained $50 \mathrm{mM}$ Tris- $\mathrm{HCl}$ ( $\mathrm{pH} 7.5), 0.018 \mathrm{mM}{ }^{14}[\mathrm{C}]$ Ado $(58 \mathrm{mCi} / \mathrm{mmole})$, $1 \mathrm{mM}$ ATP, $0.5 \mathrm{mM} \mathrm{MgCl}_{2}, 0.005 \mathrm{mM}$ erythro-9-(2-hydroxy3 -nonyl)-adenine (EHNA), $0.1 \mathrm{mM}$ adenosine $5^{\prime}-(\alpha, \beta$ methylene)-diphosphate (AMP-CP), and supernatant (45$60 \mu \mathrm{g}$ protein). EHNA and AMP-CP inhibit adenosine deaminase and 5'nucleotidase, respectively, enzymes from PBMC that are involved in purine metabolism and that can alter assay results by consuming the assay substrate. The reaction mixtures were incubated for 10 minutes at $37^{\circ} \mathrm{C}$, then stopped by heating at $100^{\circ} \mathrm{C}$ for 1 minute. After centrifugation at $12,000 \mathrm{rpm}$ for 5 minutes, $0.05 \mathrm{~mL}$ of cleared supernatant was injected into the HPLC apparatus to separate the labeled products. We used a Vista 5500 instrument (Varian, Palo Alto, Calif,USA), equipped with a UV detector at $254 \mathrm{~nm}$ and a Supelcosil $\mathrm{C}_{18}$ column $5 \mu \mathrm{m}(250 \times 4.6 \mathrm{~mm})$; the products were eluted with $92 \%$ $10 \mathrm{mM} \mathrm{KH}_{2} \mathrm{PO}_{4}$ (pH 5.5) buffer and $8 \%$ ethanol at a flow rate of $1.5 \mathrm{~mL} / \mathrm{min}$. The labeled AMP was eluted from the chromatographic column, collected, added to scintillation liquid, and radioactivity was determined using a 1500 TriCarb beta-counter (Hewlett-Packard, Palo Alto, Calif, USA).

To test for AK activity: the reactions contained $50 \mathrm{mM}$ MOPS (pH 7.4), $3 \mathrm{mM} \mathrm{MgCl}_{2}, 0.15 \mathrm{M} \mathrm{KCl,} 3 \mathrm{mM}$ ATP, $0.3 \mathrm{mM}$ phosphoenolpyruvate (PEP), 0.22 M NADH, 0.6 IU pyruvate kinase $(\mathrm{PK})$, and 0.6 IU lactate dehydrogenase (LDH) and suitable aliquots of supernatant $(20-30 \mu \mathrm{g}$ proteins). AK activity was determined using a spectrophotometric method by following the decrement at $340 \mathrm{~nm}$ for 15 minutes at $37^{\circ} \mathrm{C}$.

The activities of all enzymes were expressed as ${ }^{-}$moles of product formed in $1 \mathrm{~h} / 10^{6}$ cells.

2.4. Protein Determination Assay. Total protein was determined in samples using the Bradford assay [27] with bovine serum albumin as a standard.

2.5. Statistical Analysis. One-way analysis of variance (ANOVA) or nonparametric Kruskal-Wallis analysis was used to determine the significance of differences among the groups. Differences between means with $P<.05$ were considered statistically significant. Statistical analysis was performed using PRISM 4.00 for Windows (GraphPad Software, San Diego, Calif, USA).

\section{Results}

Most (99\%) of cells survived treatment with EMFs, which was comparable to survival under control conditions. Table 1 shows the total protein content and ecto- $5^{\prime}-\mathrm{NT}, \mathrm{ADA}, \mathrm{AdK}$, and AK enzymatic activities of pooled human PBMCs for T0 


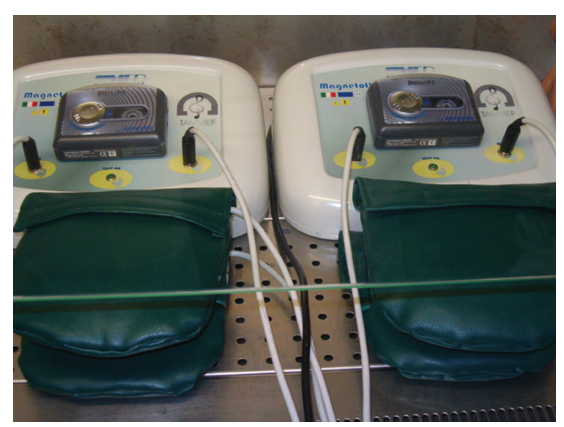

(a)

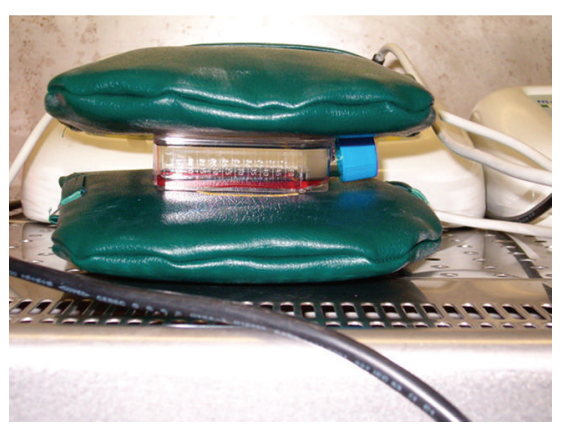

(b)

FIgURE 2: The apparatus used to generate the ELF EMFs and TAMMEFs (a). Cells were exposed to EMFs for 30 minutes (b) at room temperature.

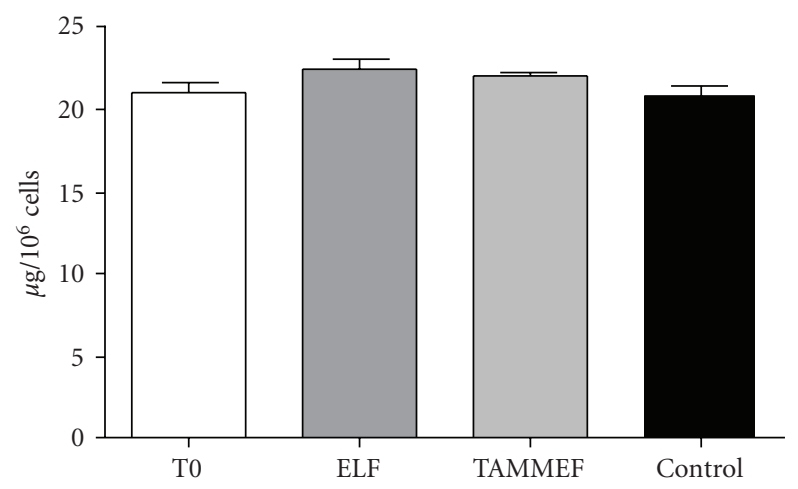

Figure 3: Total protein content $\left(\mu \mathrm{g} / 10^{6}\right.$ PBMCs; mean \pm SD of five independent experiments) of T0 cells, control cells, and cells treated with ELF EMFs and TAMMEFs.

and control cells as well as for cells treated with ELF EMFs and TAMMEFs.

The protein content increased after both EMF treatments compared to T0 and control cells, but the increase was not significant. Ecto-5' -NT, ADA, and AdK activity did not differ among the samples. However, AK activity was significantly higher $(P<.05)$ after ELF EMF treatment, with an increase of about $89 \%$ compared to T0 cells and $102 \%$ compared to control cells. In contrast, AK activity was slightly reduced $(0.2 \%)$ after TAMMEF treatment compared to T0 cells. The values shown in Table 1 are also depicted in Figures 3 and 4 as histograms in order to better illustrate the differences between the groups.

\section{Discussion}

In the present study, we evaluated the influence of ELF EMFs (at $100 \mathrm{~Hz}$ ) and TAMMEFs (with variable frequency) on the cellular metabolism of PBMCs. The total protein content and the activities of enzymes involved in purine metabolism were determined and compared in cells treated with ELF EMFs and TAMMEFs, as well as in control cells (T0 and control).

The small increase in the protein content of cells after treatment with either type of EMF can be attributed to accelerated cellular metabolism, as demonstrated previously by others [28]. It has also been shown previously that exposure to ELF EMFs can affect cell proliferation, cell cycle regulation, and differentiation, although the specific effects on health have not been determined. The mechanisms underlying the interactions of EMFs on living cells and organisms are yet unknown; until now, reports have presented largely theoretical rather than experimental observations.

The enzymes ecto-5'-NT, AdK, and ADA showed no significant changes in activity compared to controls regardless of EMF treatment. Other enzymes, such as glycolytic enzymes in human erythrocytes treated with $50 \mathrm{~Hz}$ EMF, have also been reported to be unchanged following EMF exposure [29]. In contrast, cells treated with ELF EMFs in our study showed an increase in AK activity; this enzyme is involved in nucleotide metabolism, which regulates the homeostasis of adenylic nucleotides, thus contributing to the cellular energy charge. AK is a well-studied enzyme [28]. A study of the effects of ELF $(75 \mathrm{~Hz})$ EMFs on AK activity in bovine retinal rods [30] reported a sharp decrease of its activity (approximately 55\%) relative to nonexposed control cells: this effect was observed only for AK bound to the retinal membrane, for when the AK was extracted from the membranes using Triton X-100, the enzymatic activity was no longer affected much by ELF EMFs. Based on these observations, the authors suggest that effects of the EMF are influenced by the organization and structure of the cellular membrane.

In our experiments, AK activity was higher in PBMCs treated with ELF EMFs compared to T0 and control cells. This could indicate that ELF EMFs s affect the stability of the cell's electrical charge, and we hypothesize that the tendency of AK activity to increase upon exposure to ELF EMFs is a direct consequence of cellular mechanisms that work to restore intracellular equilibrium. Magnetic field variations induce EMFs that act on the electrical charges in the cell, such as ions, free radicals, and dipolar structures. These charges are affected by the induced electromotive forces within the constraints of the cellular environment, possibly modifying cellular function. Other investigators who have studied the effects of ELFs on the cell's bioenergetic system [31, 32] have 
TABLE 1: Total protein content and activities of enzymes involved in purine metabolism in human PBMCs for T0 cells, control cells, and cells treated with ELF EMFs and TAMMEFs. Data is shown as the mean \pm SD of five independent experiments, ${ }^{*} P<.05$ compared with T0 and with control.

\begin{tabular}{|c|c|c|c|c|c|}
\hline & $\begin{array}{l}\text { Total protein } \\
\mu \mathrm{g} / 10^{6} \text { cells }\end{array}$ & $\begin{array}{c}\text { ecto- } 5^{\prime}-\mathrm{NT} \\
\mu \mathrm{mol} / \mathrm{h} / 10^{6} \text { cells }\end{array}$ & $\begin{array}{c}\text { ADA } \\
\mu \mathrm{mol} / \mathrm{h} / 10^{6} \text { cells }\end{array}$ & $\begin{array}{c}\text { AdK } \mu \mathrm{mol} / \mathrm{h} / 10^{6} \\
\text { cell }\end{array}$ & $\begin{array}{c}\mathrm{AK} \mu \mathrm{mol} / \mathrm{h} / 10^{6} \\
\text { cells }\end{array}$ \\
\hline T0 & $21.05 \pm 0.79$ & $5.83 \pm 0.82$ & $27.40 \pm 1.62$ & $2.08 \pm 0.42$ & $398.71 \pm 75.02$ \\
\hline $\mathrm{ELF}(100 \mathrm{~Hz})$ & $22.46 \pm 0.68$ & $6.46 \pm 0.86$ & $31.49 \pm 0.97$ & $2.89 \pm 0.41$ & $755.95 \pm 47.42 *$ \\
\hline TAMMEF & $22.05 \pm 0.38$ & $7.45 \pm 0.42$ & $33.07 \pm 1.66$ & $2.63 \pm 0.42$ & $388.36 \pm 69.76$ \\
\hline CONTROL & $20.86 \pm 0.65$ & $6.11 \pm 0.83$ & $29.64 \pm 2.50$ & $1.76 \pm 0.33$ & $373.87 \pm 75.01$ \\
\hline
\end{tabular}

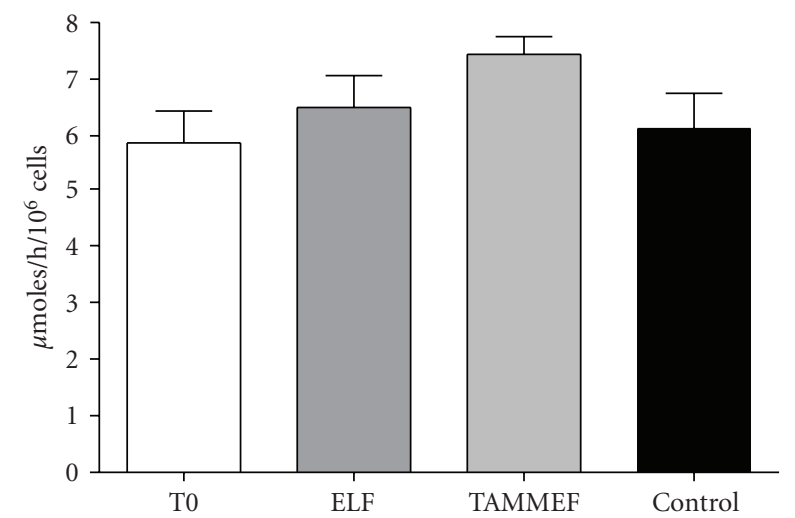

(a)

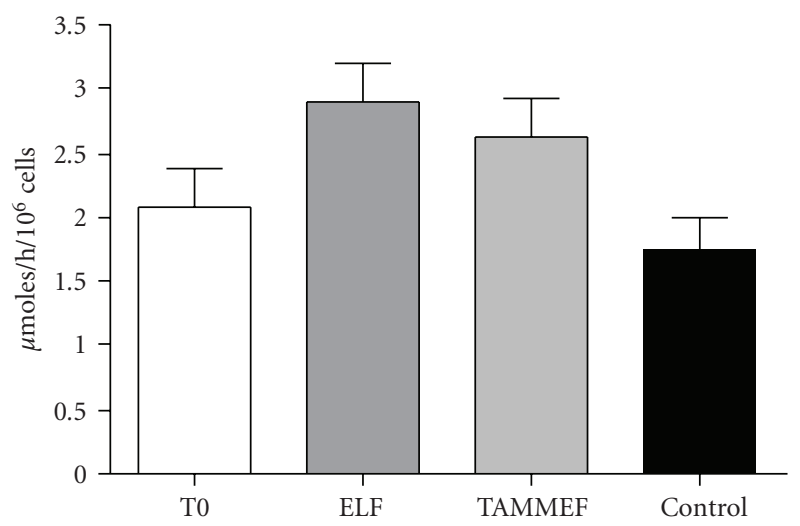

(c)

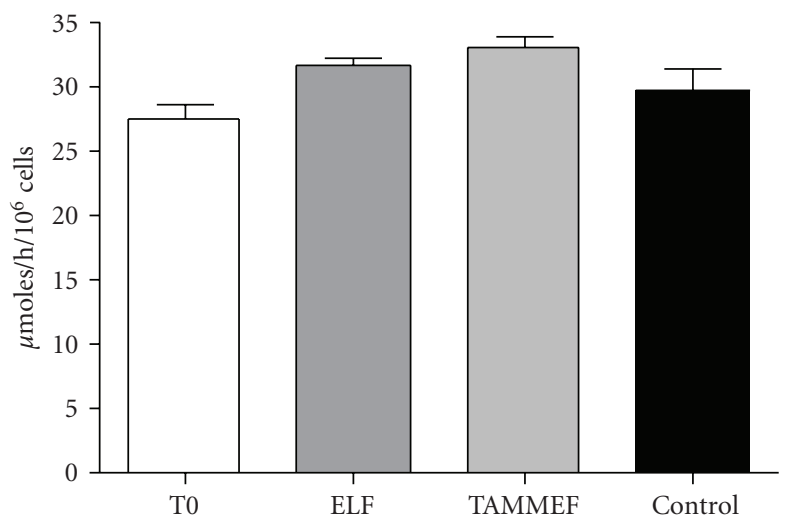

(b)

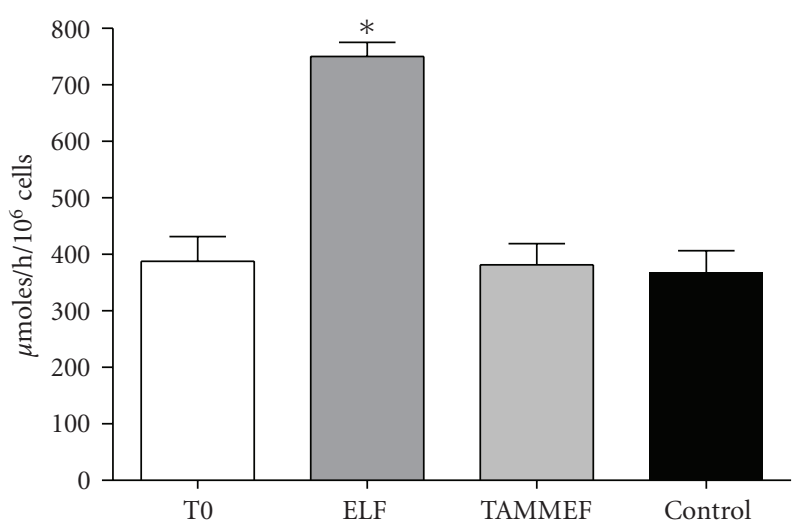

(d)

Figure 4: Enzymatic activity ( $\mu \mathrm{mol} / \mathrm{h} / 10^{6}$ PMBCs; mean \pm SD of five independent experiments) of ECTO-5' $-\mathrm{NT}$ (a), ADA (b), AdK (c), and AK (d) in T0 cells, control cells, and cells treated with ELF EMFs and TAMMEFs, ${ }^{*} P<.05$ compared with T0 and with control.

also reported increases in the activity of enzymes involved in cellular respiration, such as activation of cytocrome C oxidase [33].

Exposure of PMBCs to TAMMEFs does not increase AK activity; rather, there is a small decrease compared to the control. Thus, TAMMEF does not interfere with the cell's energetic and metabolic state and may in fact be useful for stimulating and maintaining the homeostatic response.

The data presented here hints at the potential for using TAMMEFs therapeutically.

Further research, with a larger sample size, is needed for further investigations, toward the structural and molecular sites of action, in native or stimulated cells, as in the presence of optimal concentration of phytohemagglutinin (PHA).

\section{Acknowledgments}

The authors thank Paul Kretchmer (Ph.D.), the Managing Director San Francisco Edit (kretchmer@sfedit.net) for the assistance in editing this manuscript. This work was supported in part by a contribution of the Fondazione Monte dei Paschi di Siena, Siena, Italy. 


\section{References}

[1] H. E. Lundager Madsen, "Influence of magnetic field on the precipitation of some inorganic salts," Journal of Crystal Growth, vol. 152, pp. 94-100, 1995.

[2] C. Eichwald and J. Walleczek, "Magnetic field perturbations as a tool for controlling enzyme-regulated and oscillatory biochemical reactions," Biophys Chem., vol. 14, pp. 209-224, 1998.

[3] H. Berg, "Problems of weak electromagnetic field effects in cell biology," Bioelectrochemistry and Bioenergetics, vol. 48, pp. 355-360, 1999.

[4] G. Katsir, S. C. Baram, and A. H. Parola, "Effect of sinusoidally varying magnetic fields on cell proliferation and adenosine deaminase specific activity," Bioelectromagnetics, vol. 19, no. 1, pp. 46-52, 1998.

[5] M. A. Macri and S. Di Luzio, "Biological effects of electromagnetic fields," International Journal of Immunopathology and Pharmacology, vol. 15, pp. 95-105, 2002.

[6] P. Volpe, "Interactions of zero-frequency and oscillating magnetic fields with biostructures and biosystems," Photochemical and Photobiological Sciences, vol. 2, no. 6, pp. 637-648, 2003.

[7] N. Giordano, E. Battisti, S. Geraci, et al., "Effect of electromagnetic fields on bone mineral density and biochemical markers of bone turnover in osteoporosis: a single-blind, randomized pilot study," Current Therapeutic Research, vol. 62, pp. 187193, 2001.

[8] N. Giordano, E. Battisti, S. Geraci, et al., "Analgesicantiinflammatory effect of $100 \mathrm{~Hz}$ variable magnetic field in R.A.," Clinical and Experimental Rheumatology, vol. 18, p. 263, 2000.

[9] M. Rigato, E. Battisti, M. Fortunato, et al., "Comparison between the analgesic and therapeutic effects of a musically modulated electromagnetic field (TAMMEF) and those of a $100 \mathrm{~Hz}$ electromagnetic field: blind experiment on patients suffering from cervical spondylosis or shoulder periarthritis," Journal of Medical Engineering and Technology, vol. 26, pp. 253-258, 2002.

[10] E. Battisti, E. Piazza, M. Rigato, et al., "Efficacy and safety of a musically modulated electromagnetic field (TAMMEF) in patients affected by knee osteoarthritis," Clinical and Experimental Rheumatology, vol. 22, pp. 568-572, 2004.

[11] M. Simkó and M. O. Mattsson, "Extremely low frequency electromagnetic fields as effectors of cellular responses in vitro: possible immune cell activation," Journal of Cellular Biochemistry, vol. 93, pp. 83-92, 2004.

[12] R. Cadossi, F. Bersani, A. Cossarizza, et al., "Lymphocytes and low-frequency electromagnetic fields," FASEB Journal, vol. 6, pp. 2667-2674, 1992.

[13] M. Capri, E. Scarcella, C. Fumelli, et al., "In vitro exposure of human lymphocytes to $900 \mathrm{MHz}$ CW and GSM modulated radio-frequency: studies of proliferation, apoptosis and mitochondrial membrane potential," Radiation Research, vol. 162, no. 2, pp. 211-218, 2004.

[14] M. R. Scarfi, M. B. Lioi, O. Zeni, et al., "Micronucleus frequency and cell proliferation in human lymphocytes exposed to $50 \mathrm{~Hz}$ sinusoidal magnetic fields," Health Physics, vol. 76, pp. 244-250, 1999.

[15] M. Capri, E. Scarcella, C. Fumelli, et al., "Lack of genotoxic effects (micrinucleus induction) in human lymphocytes exposed in vitro to $900 \mathrm{MHz}$ electromagnetic fields," Radiation Research, vol. 162, no. 2, pp. 211-218, 2004.
[16] M. Fiorani, O. Cantoni, P. Sestili, et al., "Electric and/or magnetic field effects on DNA structure and function in cultured human cells," Mutation Research, vol. 282, no. 1, pp. 25-29, 1992.

[17] A. Zrimec, I. Jerman, and G. Lahajnar, "Alternating electric fields stimulate ATP synthesis in Escherichia coli," Cellular and Molecular Biology Letters, vol. 7, no. 1, pp. 172-174, 2002.

[18] S. Ravera, E. Repaci, A. Morelli, et al., "Effects of extremely low frequency electromagnetic fields on the adenylate kinase activity of rod outer segment of bovine retina," Bioelectromagnetics, vol. 25, pp. 545-551, 2004.

[19] S. Ravera, E. Repaci, A. Morelli, et al., "Electromagnetic field of extremely low frequency decreased adenylate kinase activity in retinal rod outer segment membranes," Bioelectrochemistry, vol. 63, pp. 317-320, 2004.

[20] A. Conte, M. Petrini, P. Zaniol, et al., "Effects of pulsed electromagnetic fields on the adenine nucleotide pool and energy charge in cells in culture," in Proceedings of the Purine and Pyrimidine Metabolism VII, pp. 305-308, 1991.

[21] J. R. S. Arch and E. A. Newsholme, "Activities and some properties of $5^{\prime}$-nucleotidase, adenosine kinase and adenosine deaminase in tissues from vertebrates and invertebrates in relation to the control of the concentration and the physiological role of adenosine," Biochemical Journal, vol. 174, pp. 965-977, 1978.

[22] Y. Worku and A. C. Newby, "The mechanism of adenosine production in rat polymorphonuclear leucocytes," Biochemical Journal, vol. 214, pp. 325-330, 1983.

[23] R. J. Zeleznikar, R. A. Heyman, R. M. Graef, et al., "Evidence for compartmentalized adenylate kinase catalysis serving a high energy phosphoryl transfer function in rat skeletal muscle," Journal of Biological Chemistry, vol. 265, pp. 300-311, 1990.

[24] F. N. Gellerich, "The role of adenylate kinase in dynamic compartmentation of adenine nucleotides in the mitochondrial intermembrane space," FEBS Letters, vol. 297, pp. 55-58, 1992.

[25] F. Carlucci, A. Tabucchi, E. Consolmagno, et al., "Levels and variability of purine nucleotides in normal human lymphocytes," Biomedicine and Pharmacotherapy, vol. 46, pp. 109-114, 1992.

[26] D. Vannoni, A. Bernini, F. Carlucci, et al., "Enzyme activities controlling adenosine levels in normal and neoplastic tissues," Medical Oncology, vol. 21, pp. 187-195, 2004.

[27] M. M. Bradford, "A rapid and sensitive method for the quantitation of microgram quantities of protein utilizing the principle of protein dye binding," Analytical Biochemistry, vol. 72, pp. 248-254, 1976.

[28] M. Simkó and M. O. Mattsson, "Extremely low frequency electromagnetic fields as effectors of cellular responses in vitro: possible immune cell activation," Journal of Cellular Biochemistry, vol. 93, pp. 83-92, 2004.

[29] M. Dachà, A. Accorsi, C. Pierotti, et al., "Studies on the possible biological effects of $50 \mathrm{~Hz}$ electric and/or magnetic fields: evaluation of some glycolytic enzymes, glycolytic flux, energy and oxido-reductive potentials in human erythrocytes exposed in vitro to power frequency fields," Bioelectromagnetics, vol. 14, pp. 383-391, 1993.

[30] S. Ravera, E. Repaci, A. Morelli, et al., "Electromagnetic field of extremely low frequency decreased adenylate kinase activity in retinal rod outer segment membranes," Bioelectrochemistry, vol. 63, pp. 317-320, 2004.

[31] I. Detlavs, L. Dombrovska, A. Turauska, et al., "Experimental study of the effects of radiofrequency electromagnetic fields 
on animals with soft tissue wounds," Science of the Total Environment, vol. 180, no. 1, pp. 35-42, 1996.

[32] H. Pafkova, J. Jerabek, I. Tejnorova, et al., "Developmental effects of magnetic field $(50 \mathrm{~Hz})$ in combination with ionizing radiation and chemical teratogens," Toxicology Letters, vol. 88, pp. 313-316, 1996.

[33] B. Nossol, G. Buse, and J. Silny, "Influence of weak static and $50 \mathrm{~Hz}$ magnetic fields on the redox activity of cytochrome-C oxidase," Bioelectromagnetics, vol. 14, pp. 383-391, 1993. 

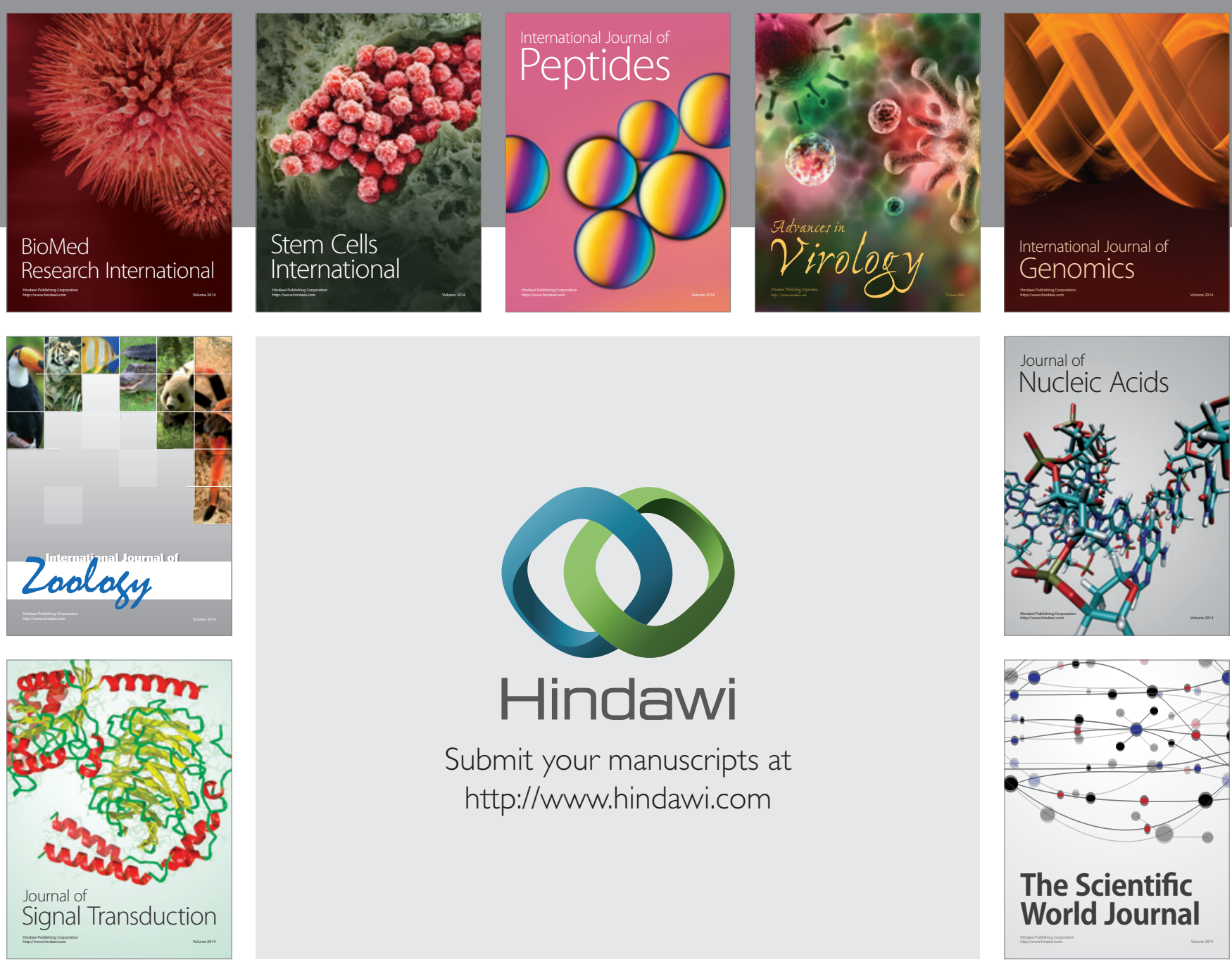

Submit your manuscripts at

http://www.hindawi.com
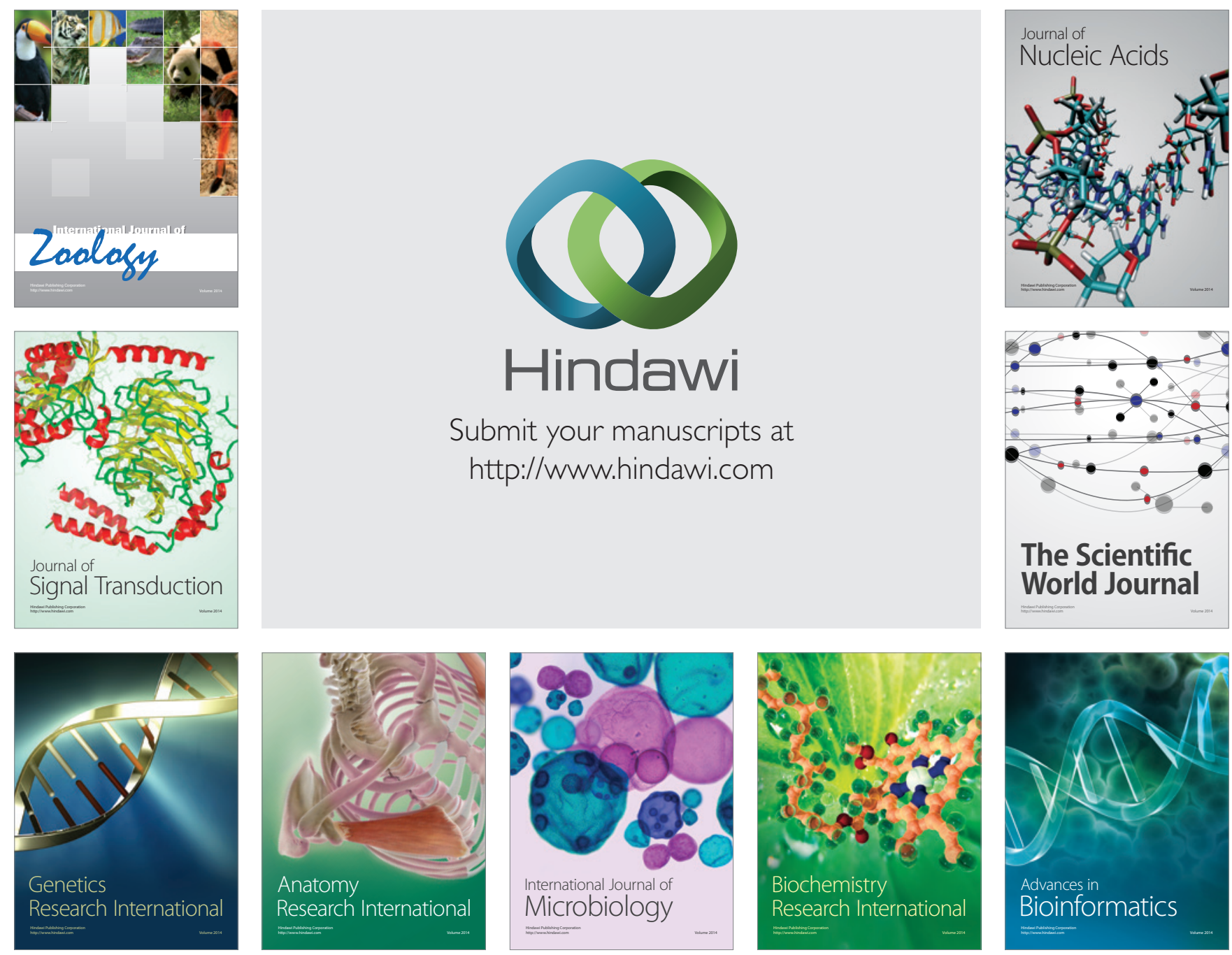

The Scientific World Journal
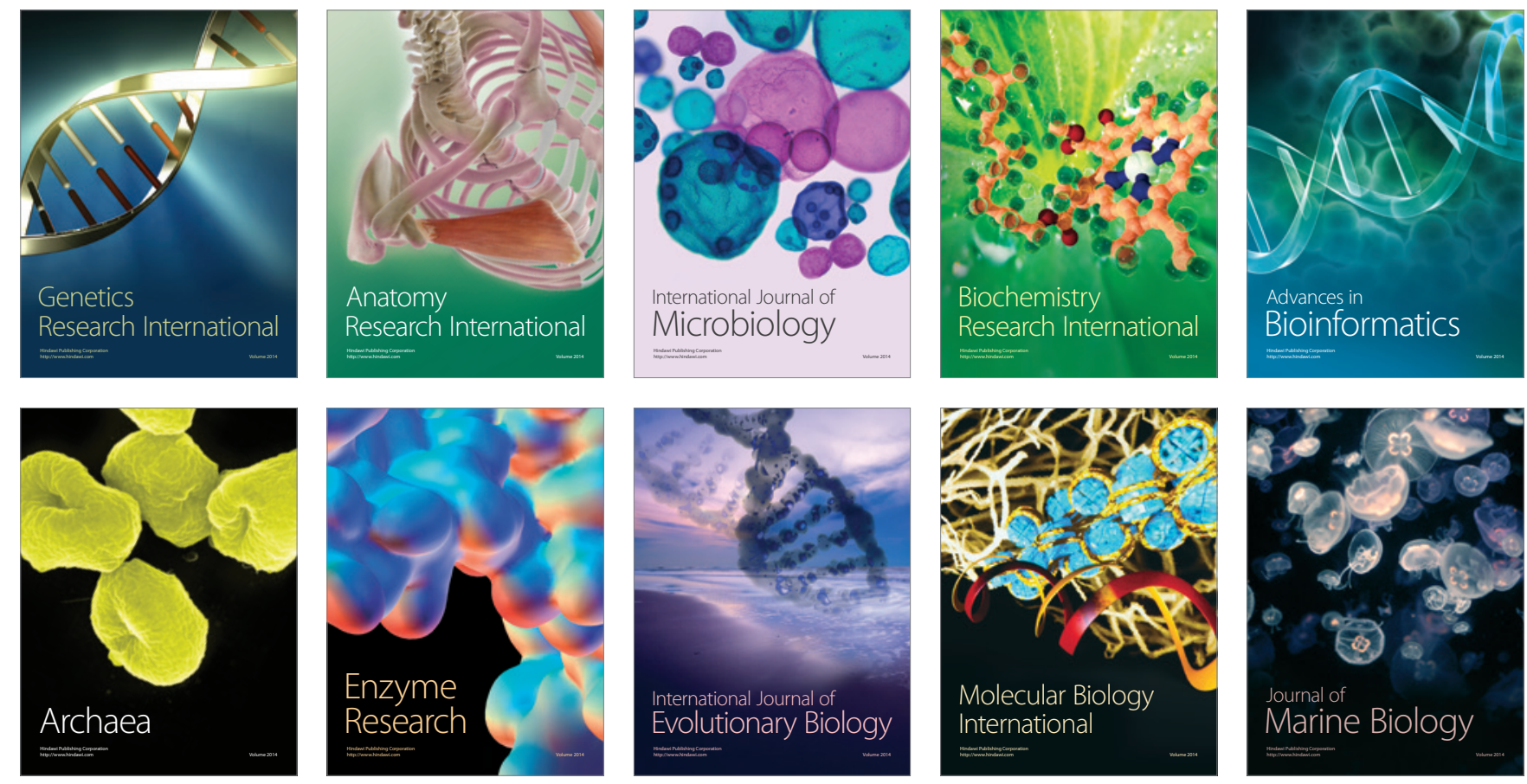